\title{
Graphics Thinking in Engineering Graphics Education
}

\author{
Chao-yong Guo ${ }^{1}$, Bao-hui Gao ${ }^{2}$ \\ ${ }^{1}$ Department of Vehicle and Electrical Engineering, Shijiazhuang Mechanical Engineering College, Shijiazhuang, China \\ 2 Department of Mechanical Engineering, Beijing Institute of Technology, Beijing, China
}

\begin{abstract}
The importance of graphics thinking to the reform and development of engineering graphics education is pointed out. Using information theory, from the point of the relationship between thinking and information, the paper systematically discusses the implementing principle of graphics thinking in engineering graphics education. The graphics thinking methods and its characteristics are illustrated, and the methods for graphics thinking training are described concretely.
\end{abstract}

Index Terms - Graphics Thinking, Graphics Education, Graphics Teaching.

\section{Introduction}

Engineering graphics is the study of engineering technology in the field of theory and application of related engineering drawings of a discipline, and computer science, mathematics and engineering science and thinking science and other multi-disciplinary cross a discipline. It as a foundation for engineering courses in training students' space thinking, abstract logical thinking with image thinking ability played an important role. In the face of the rapid development of science and technology and modern education to the new requirement of the personnel training to examine engineering graphics, deeply from the graphics knowledge in the field of the overall structure and the overall function, multi-dimensional and multi-level study of graphics thinking method, turn to the multi-dimensional thinking by a single thinking, strengthen the training of the thinking in graphics teaching, should be an important aspect of engineering graphics teaching reform.

Graphics thinking is the scientific thinking of engineering graphics, is the thinking mechanism of understanding the regulation inside graphics; graphics thinking is logic thinking with images. It has quality of images, logic, interaction, integration and fuzz. Its thinking forms are the single form with "images, association, pictures", and the composite form with "ideas, judgment, reasoning"; graphics thinking takes the modem brain science as the basic theory, thinking science as the leading theory, engineering graphics as main theory, practical science as the supporting theory. Graphics thinking is the important method to lead engineering graphics to promote thinking and teaching. These ideas have been agreed in the field of graphics education.

Recently, the situation which graphics thinking leads engineering graphics shows that it is very important to let students study efficiently, to grasp graphics knowledge, to optimize thinking, to foster thinking ability and quality.

This paper will discuss the implementation of graphics thinking in engineering graphics.

\section{Enlarge Information Amount and Enforce Memory}

The acceptation of thinking information ( graphics knowledge ) is the foundation of creative thinking and logical thinking. The following methods can be used to enforce memory.

Facing a large amount of information, if and only if the students' thinking is active, the accepted information can be changed to thinking information and to be memorized. The interests and attentions of students grow when information amount becomes larger, then students' thinking will be active, and the interaction will happen. Engineering graphics has the quality of images, the establishment and statement of the ideas, especially the foundation of projection theory, should be the quality of science and theory. And the information amount should be enlarged.

When teacher shows students the examples, he should stop it at proper time. The information given to student is entropy information, incomplete information. Students should think to get complete thinking information.

Relevant information method, exercises and examples are controlled by the goals. The control goals of quality and quantity are the relevant information. So, exercises should not be too many, in order to avoid to restrain the information.

Joint method, it is a very efficient method to bring the left and right brain into joint thinking activity. When an idea is given, the space images (models), theoretical images (projection drawing) and abstract ideas (relevant theorems) should be used together, in order to reach the expected goals.

Training to grasp the shape quality, in teaching procedure, the training to grasp the shape quality can foster the ability to grab information and enlarge the information contact. Apart from the normal solid measuring drawing the instant looking drawing can be used. Students are very interested in it, feel fresh, and concentrate on it. The better result can be got.

Comparing method, to camper the object in engineering graphics field can make the thinking information be memorized through neutral network by its class. It is easy to get it at any time.

The method mentioned above can be induced as knowing widely and memorizing forcibly, to reflect the thinking form of "information centralized".

\section{Information Analogy and Image Association}

Association is the thinking activity through thinking information analogy, to call the similar object, is the foundation image and logical inference, is the spring of 
creativity. The memory of thinking information is the necessary condition of association optimization.

Furthermore, there is a question about what kind of information should be abstracted and how to abstract it. That is the direction and the method of association activity. It is the reflection of the association ability.

There are following kinds of analogy association in engineering graphics.

Similar association is the association about the similar equality among different objects, is the relater association controlled by the same regulation. The similarity and common are its character, such as the cone (cylinder) and pyramid (prism).

Comparing association is the association abased on the difference among objects, for example, the raised and concave structure of the same solid.

Approach association is the association characterized by the unchanged quality of objects, such as the full intersection and apart intersection of two cylinders.

Isomorphic association is the association characterized by the isomorphic quality of objects. If the space structures of two objects are isomorphic, their projection drawings are also isomorphic. For example, the space streetcars nag the projection drawings of a prism and pyramid is isomorphic.

Fuzz association is the feeling association characterized by apart similarity of objects. Naturally, quick inference is its character, but mistakes can't be avoided. For example, students often think by their projection drawings, two perpendicular cylinders cut by one another as a sphere, however, it can stimulate.

\section{Quit Before Going Forward, Inference Imagination}

Imagination is the ability to grasp the relationship among objects, and the ability to create new objects, is the practical element of science research, is the procedure to create new idea by reproducing, changing and combining the thinking information in the brain. Imagination in engineering graphics includes the study imagination (reconstructive imagination) and the creativeness imagination (creative imagination).

Reconstructive imagination is to reconstruct the idea created by other persons, based on the analysis of unit elements, with thinking information of association, by the thinking method of images and ideas.

The character of this imagination is not creation, but understanding, it is very important to the ability of studying and grasping knowledge. Therefore, it is widely used in engineering graphics. For example, to figure out the third projection of a solid by two given projections, to draw a certain projection view of a component, to draw a assembly drawing by its component's drawing and so on. Which reflect the thinking method of "quitting before going forward" in image thinking activity.

Cretonne imagination is the "real" thinking. It is to associate the similar points of irrelevant objects.

To find out the basic connection by change, to simulate the inspiration, to create new ideas, in border to faster the thinking ability, some exercises which have no enough condition and definite results, but with certain purpose, have been put into engineering graphics. For example, to draw two other projections by one given projection of an object, and the comprehensive exercises which have more than one solution. The ability to solve these problems is based on the width of the thinking and the inspiration (thinking quality), the depth of the knowledge grasping (the quality of thinking information memory) and the psychological quality of knowing. These qualities should be fostered, trained developed and stimulated by leaching activity.

The fostering of reconstructive imagination is easy to cause thinking in a certain may, to form convergent thinking. It has good and bad factors to the fostering of thinking quality, the straining of creative thinking ability can overcome the certain thinking may, to form the divergent thinking. But it should be based on the former, in engineering graphics, both of them are important, and the proportion should be suitable.

\section{Alternative Leading, Interactive Thinking}

From the point of dialectical relation between thinking in images and abstract thinking, the combined thinking form can be found in engineering graphics --- interactive thinking form. Then, the thinking activity can be more active, and the thinking and teaching results can be much better.

Thinking in images is dried by ideas. Generally speaking, thinking in images should take the abstract thinking as the leading to censure the quality of science and creativeness, in border to reflect the essence of objects. Therefore, the advantage of thinking in images can only be produced and developed under the implementation condition of abstract thinking. Although engineering graphics is not as logical as mathematics, there are still a lot of abstract logical elements in it, and a lot of the problems about the relations of space geometric elements. So it is difficult to solve them only depend on space thinking. Ideas and theorist should be the logical regulation to inspirit and lead the thinking in images, to eliminate and correct thinking mistakes, to make thinking act correctly.

Abstract thinking is lead by images. Images can show the procedure of abstract logical thinking. They are helpful to solve problems, and are tools of abstract thinking. Thinking in images can lead invention and creation, can correct the possible mistakes in abstract thinking. The purpose to use images to lead thinking in engineering graphics is to study, to understand and grasp new ideas and theory, to search the method to solve the problems. For some relatively difficult combined exercises, if a space image can be given, the main point of the problem can be found. It is very helpful to thinning direction, to the solution of the problem.

These two aspects mentioned above are a relevant entirety, in the whole procedure of thinking, they act alternatively, make up each other. The thinking result is whole effect, not the effect to put them together simply. It has great significance to the development of brain function and the fostering of thinking ability. 


\section{Conclusions}

Engineering graphics teaching to cultivate students' innovation ability, its core is to develop the students' ability of scientific thinking, and engineering graphics inherent threedimensional form and subject that the two-dimensional graphics transformation, makes it especially suitable for making the diversity of the cultivation of thinking ability. Therefore, must be knowledge of engineering graphics and the cultivation of thinking ability in the equally important position.

In this paper, we give the definition of graphics thinking, expounds the method of graphics thinking, illustrates the characteristics of graphics thinking, describes the graphics thinking training methods.

So far, the research on graphics thinking is theoretical and inadequate, there are many questions worth further being discussed.

\section{References}

[1] Tong Bingshu and Gao Shufeng. "Cultivate students innovation ability in teaching of engineering graphics. Journal of engineering graphics, 2008 (6): pp1-6.(in Chinese)

[2] Jiang Guirong and Zhao Bingli. "Research on the innovative thinking method in engineering graphics". Teaching and research, 2005, vol28 (5): pp436-438. (in Chinese)

[3] Sun Wei, Chen Jinchang and Chen Liang. "Engineering drawing science exploration and practice in strengthening configuration creative design ability". Journal of Donghua University. 2010, vol36 (4): pp457461. (in Chinese)

[4] Wang Xiuying, Bai Haiying and Zhang Xiuzhi. "The cultivation of innovative talents of engineering graphics:The comprehensive practice" .Journal of engineering graphics, 2009 (5):pp149-152. (in Chinese) 